\title{
Recovery of Iron from Pyrolusite Leaching Slag by a Lab-Scale Circulation Process of Oxalic Acid Leaching and Ultraviolet Irradiation
}

\author{
Biao Deng, Bozhi Wang, Shijun Su, Sanglan Ding and Weiyi Sun * \\ College of Architecture \& Environment, Sichuan University, Chengdu 610065, China; \\ dengbiaoscu@163.com (B.D.); wbzscu@163.com (B.W.); ssjscu@163.com (S.S.); dslscu@163.com (S.D.) \\ * Correspondence: sunweiyi@scu.edu.cn; Tel.: +86-028-8564-7252
}

Received: 11 November 2017; Accepted: 21 December 2017; Published: 26 December 2017

\begin{abstract}
Pyrolusite leaching slag is a Fe-containing slag generated from pyrolusite leaching process with $\mathrm{SO}_{2}$. Recovery of iron from the slag not only has economic benefit, but also prevents the secondary pollution to the environment. A novel lab-scale cyclic process for recovering iron from pyrolusite leaching slag was introduced. The process contains two steps: (1) iron was leached with oxalic acid and $\left[\mathrm{Fe}\left(\mathrm{C}_{2} \mathrm{O}_{4}\right) \mathrm{n}\right]^{(3-2 \mathrm{n})+}$ solution was generated; (2) the $\left[\mathrm{Fe}\left(\mathrm{C}_{2} \mathrm{O}_{4}\right) \mathrm{n}\right]^{(3-2 \mathrm{n})+}$ solution was irradiated by ultraviolet and ferrous oxalate precipitation were obtained. The effect of operation parameter on leaching and irradiation process were studied separately. In the leaching process, the optimal solid/liquid ratio, oxalic acid concentration, leaching temperature, stirring rate, and leaching time are $1: 50,0.40 \mathrm{~mol} / \mathrm{L}, 95^{\circ} \mathrm{C}, 300 \mathrm{r} / \mathrm{min}$, and $3 \mathrm{~h}$, respectively. In the irradiation process, the best irradiation wavelength, Fe/oxalic acid molar ratio and irradiation time are $254 \mathrm{~nm}$, 1:4, and $30 \mathrm{~min}$. Besides, a test of 9 continuous cycles was carried out and the performance and material balance of the combined process were investigated. The results showed that the cyclic process is entirely feasible and prove to be stable producing, and ferrous oxalate of $99.32 \%$ purity. Material balance indicated that $95.17 \%$ of iron was recovered in the form of $\mathrm{FeC}_{2} \mathrm{O}_{4} \cdot 2 \mathrm{H}_{2} \mathrm{O}$, and the recovery efficiency of oxalic acid was $58.52 \%$.
\end{abstract}

Keywords: recovering iron; pyrolusite leaching slag; ferrous oxalate; oxalic acid; ultraviolet irradiation

\section{Introduction}

Iron is widely used in every aspect of society. Research investigate that a large amount of iron exists in manganese ore because of the similar chemical properties of iron and manganese, for example, pyrolusite [1]. As we known, pyrolusite is an important type of manganese ore, in which iron and manganese mainly exist forms are manganese dioxide, ferric oxide, and goethite, respectively. The manganese could be leached from pyrolusite by sulfur dioxide selectively [2-4]. When manganese extraction efficiency is above $90 \%$, iron extraction efficiency is less than $5 \%$ [5], which lead to iron enrichment in slag, and its grade could generally reach 10-30\% [6-8]. These slags are precious secondary resource, which are valuable for metal recovery and reuse in view of sustainable development and environment protection. Research on the recovery and utilization of iron in this slags is rarely. However, direct discharge of the slags without treatment not only causes environment pollution problems, but also leads to a great waste of a useful material resource. At present, there have some researches which focus on recovery or removal of iron from the Fe-containing slags or minerals by leaching or direct reduction [9-11], and sulfuric acid [12], nitric acid [13], and oxalic acid [14-17] were used as reductant, or by oxidation [18] and, roasting [10,19]. By way of contrast, oxalic acid has a strong acidity, good chelating ability to iron, and higher environmental benignity [20,21]. 
Ferrous oxalate has wide applications as important chemical material, such as, production of dye and colorant, raw material of novel battery electrode, and photosensitive material. With the rapid development of lithium ion battery, ferrous oxalate has gained attention as the ideal raw material for preparing $\mathrm{LiFePO}_{4}$ cathode material in recent years [22,23]. Research suggests that the stable complex of $\left[\mathrm{Fe}\left(\mathrm{C}_{2} \mathrm{O}_{4}\right)_{\mathrm{n}}\right]^{(3-2 \mathrm{n})+}$ can be obtained by using oxalic acid to leach slags. For preparing ferrous oxalate from stable complex solution of $\left[\mathrm{Fe}\left(\mathrm{C}_{2} \mathrm{O}_{4}\right)_{n}\right]^{(3-2 n)+}$, some reductants must be added, such as iron powder. This may be decrease the purity of ferrous oxalate products. In contrast, it has very high photochemical activity [24] and could be reduced directly to ferrous oxalate by ultraviolet light without any catalyst at room temperature. The reaction is quickly and conversion ratio of iron is very high.

Yu Zhang-long et al. [25] carried out an oxalic acid leaching and ultraviolet irradiation process for removing iron from red-mud successfully. However, the feasibility of this method for recovering iron from the pyrolusite leaching slag is indistinct, the feasibility, stability, and material balance of the circulation process for ferrous oxalate production from pyrolusite leaching slag using oxalic acid leaching and ultraviolet irradiation remain poorly understood.

Therefore, for recovering iron and decreasing the pollution of the slag, in this paper, a lab-scale cyclic process for recovering iron and producing ferrous oxalate from pyrolusite leaching slag by oxalic acid leaching and ultraviolet irradiation was developed. Firstly, iron was leached into solution by oxalic acid. The effects of leaching conditions on extraction efficiency, including solid/liquid ratio (L/S ratio), oxalic acid concentration, leaching temperature, and stirring rate were investigated. Secondly, the stable complex solution of $\left[\mathrm{Fe}\left(\mathrm{C}_{2} \mathrm{O}_{4}\right)_{3}\right]^{3-}$ was irradiated by ultraviolet. The optimal irradiation time and wavelength were investigated. The effects of different molar ratios of iron to oxalic acid were altered to study impact of iron and oxalic acid in irradiation experiment. Precipitate crystal morphology and phase were characterized by scanning electron microscope (SEM) and X-ray diffraction (XRD), respectively. For exploring the feasibility and stability of the lab-scale cyclic process, and obtaining enough experiment data to investigate the cycle characteristics, operation stability and material balance of the cyclic process, a test of 9 continuous cycles was adopted.

\section{Materials and Methods}

\subsection{Experimental Flow}

A schematic diagram of the technological process is shown in Figure 1. The experiment is divided into two parts, i.e., leaching of iron with oxalic acid and irradiation of leaching solution by ultraviolet light.

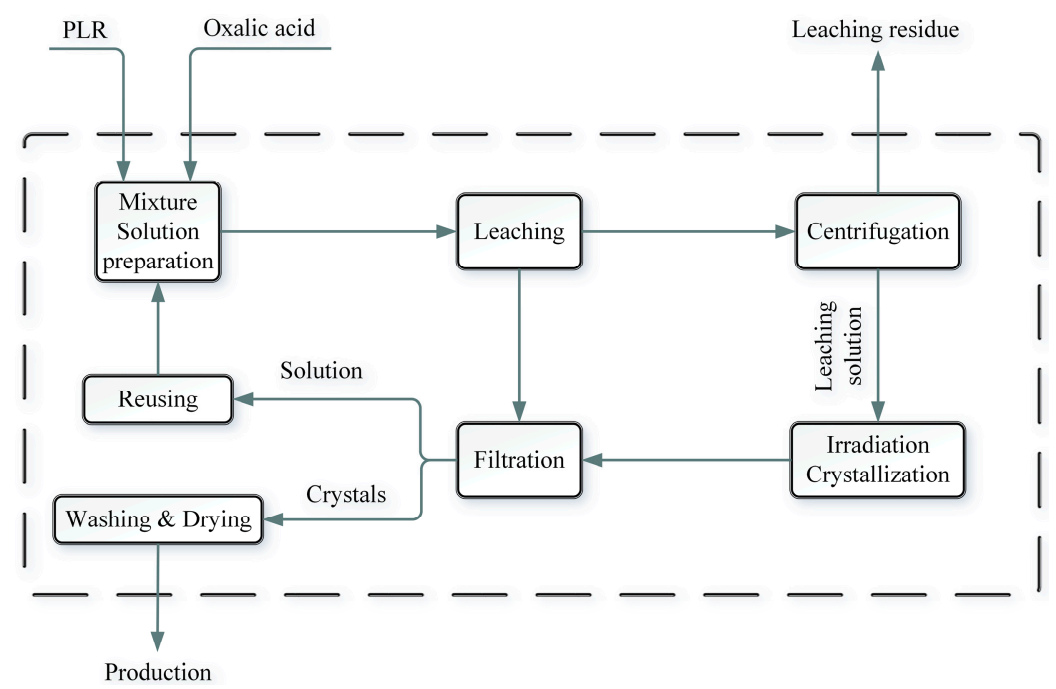

Figure 1. Schematic diagram of a cyclic process of ferrous oxalate production. 


\subsubsection{Leaching of Slag with Oxalic Acid}

The leaching process of the slag with oxalic acid was conducted in a $1000 \mathrm{~mL}$, 3-neck, round bottom flask, which was placed in a constant temperature oil bath (HH-ZK4, Gong Yi Yuhua Instrument Co., Ltd., Gongyi, China). Continuous stirring of the leaching solution was provided by a mechanical agitator (JJ-1, Jingtan Medical Instrument Co., Ltd., Jingtan, China).

\subsubsection{Irradiation Experiments}

The solution containing ferric oxalate complex was irradiated by XPA-system photochemical reactor (XPA-3, XuJiang Electromechanical Plant, Nanjing, China), and yellow crystal was separated. The yellow crystal was filtered by a suction machine (SHB-III, Beijing Kewei Yongxing Instrument Co., Ltd., Beijing, China) at the end of irradiation experiment. Then, it was dried using an electric heating air-blowing drier (101-1AB, Beijing Zhongxing Weiye Instrument Co., Ltd., Beijing, China) at $80^{\circ} \mathrm{C}$. The crystal morphology and phase of the yellow crystal were characterized by scanning electron microscope (SEM, JSM-7500F, JEOL Ltd., Tokyo, Japan) and X-ray diffractometer (XRD, EMPYREAN, Panalytical Co., Ltd., Almelo, The Netherlands), respectively. For SEM test, the yellow crystals were fixed in silk film over $4 \mathrm{~h}$ by $2.5 \%$ glutaraldehyde, and then, it was observed at an accelerating voltage of $15 \mathrm{kV}$ in vacuum condition. For XRD test, the voltage used was $40 \mathrm{kV}$, current was $40 \mathrm{~mA}$, scanning speed was $14.79 \mathrm{~s} / \mathrm{step}$, sampling interval was $0.026^{\circ}$, and two-theta range from 10 to $80^{\circ}$ with copper $(\mathrm{Cu})$ anode at $\lambda(\mathrm{Cu} \mathrm{K} \alpha)=1.540598 \AA$.

\subsection{Materials}

The pyrolusite leaching slag is produced from pyrolusite leaching process with $\mathrm{SO}_{2}$ according to our previous work [26]. The XRD pattern of slag was test, the voltage used was $35 \mathrm{kV}$, current was $30 \mathrm{~mA}$, scanning speed was $0.2 \mathrm{~s} / \mathrm{step}$, sampling interval was $0.03^{\circ}$ and two-theta range from 5 to $95^{\circ}$ with copper $(\mathrm{Cu})$ anode at $\lambda(\mathrm{Cu} \mathrm{K} \alpha)=1.54056 \AA$. The slag particle size is $80 \sim 95 \mu \mathrm{m}$. All the reagents used in this study were of analytical grade, including oxalic acid (dehydrate, $\mathrm{H}_{2} \mathrm{C}_{2} \mathrm{O}_{4} \geq 99.5 \%$, Chengdu Kelong Chemical Reagent Co., Ltd., Chengdu, China), potassium permanganate $\left(\mathrm{KMnO}_{4} \geq 99.5 \%\right.$, Chengdu Kelong Chemical Reagent Co., Ltd., Chengdu, China), 1, 10-phenanthroline, acetic acid, sodium acetate, and so on.

\subsection{Operation Parameters}

In leaching experiment, the solution volume was maintained around $1 \mathrm{~L}$. The concentration of Fe in the leaching solution was measured every $30 \mathrm{~min}$ until $3 \mathrm{~h}$.

In irradiation experiment, the concentration of Fe and oxalic acid were determined every $15 \mathrm{~min}$. The irradiation lasted $1.5 \mathrm{~h}$ for exploring optimal irradiation time and wavelength and lasted $1 \mathrm{~h}$ for studying the effect of Fe and oxalic acid concentration on the irradiation process. The ultraviolet light power was remained at $500 \mathrm{~W}$. The wavelengths of and ">420 nm" are the scope of " $420-1000 \mathrm{~nm}$ ", which was achieved by a using suitable filter.

\subsection{Sample Analysis}

Fe concentration was measured by 1,10-phenanthroline spectrophotometric method (HJ/T 345-2007) using UV-vis. spectrophotometer (V-1100D, Shanghai Meipuda Instrument Co., Ltd., Shanghai, China). Concentration of oxalic acid and grade of ferrous oxalate crystal were determined by potassium permanganate titration method. Component of the slag was characterized by X-ray fluorescence. (XRF, XRF-1800, Shimadzu Co., Ltd., Tokyo, Japan). 


\section{Results}

\subsection{Analysis of Slag}

The Figure 2 shows that main components of slag are $\mathrm{SiO}_{2}$ (JCPDS 46-1045), $\mathrm{BaSO}_{4}$ (JCPDS 76-0213) and $\mathrm{FeO}(\mathrm{OH})$ (JCPDS 81-0462). The composition of the slag was showed in Table 1 and the atomic percentage of Fe was $26.62 \%$, which was necessary for recovery.

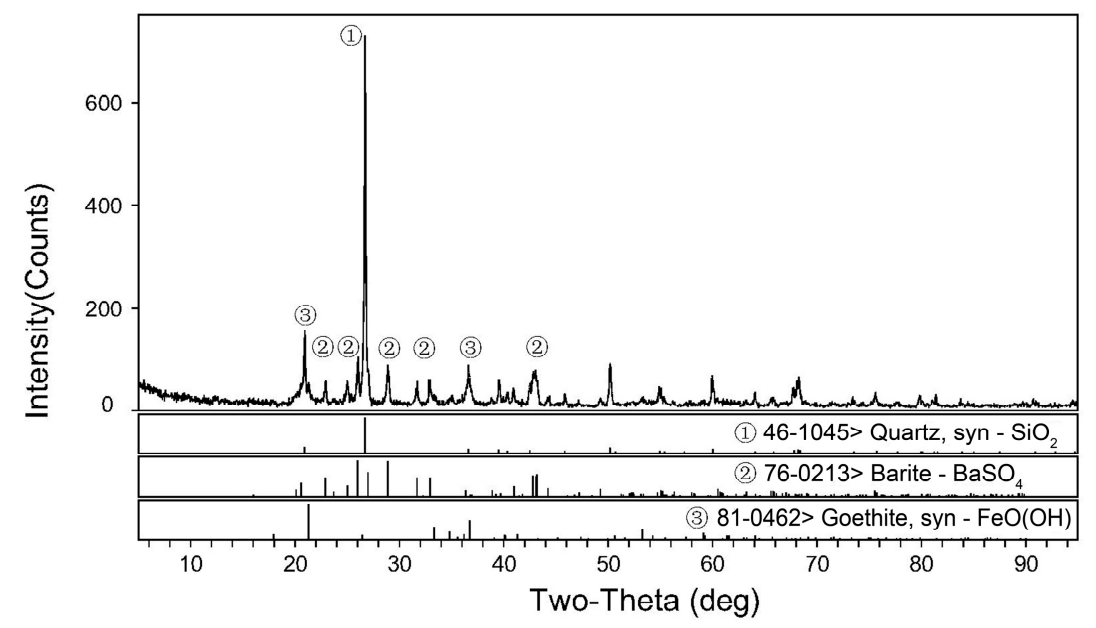

Figure 2. XRD pattern of slag.

Table 1. Compositions of slag (wt \%).

\begin{tabular}{cccccccc}
\hline Fe & $\mathbf{M n}$ & Al & Ba & K & Ti & Mg & Ca \\
\hline 26.62 & 2.6 & 1.75 & 0.49 & 0.26 & 0.09 & 0.09 & 0.08 \\
$\mathrm{Zn}$ & $\mathrm{V}$ & $\mathrm{Ni}$ & $\mathrm{Cr}$ & $\mathrm{Cu}$ & $\mathrm{Pb}$ & $\mathrm{Sr}$ & Others \\
0.044 & 0.035 & 0.03 & 0.028 & 0.02 & 0.016 & 0.014 & 67.833 \\
\hline
\end{tabular}

\subsection{Leaching of Slag with Oxalic Acid}

In leaching process, iron was leached from slag with oxalic acid (Reaction (1)), and the stable complex solution of $\left[\mathrm{Fe}\left(\mathrm{C}_{2} \mathrm{O}_{4}\right)_{n}\right]^{(3-2 n)+}$ can be generated by Reactions (2)-(4). The reactions involved in leaching process are listed, as follows $[14,16,27,28]$ :

$$
\begin{gathered}
\mathrm{FeO}(\mathrm{OH})+3 \mathrm{H}_{2} \mathrm{C}_{2} \mathrm{O}_{4} \rightarrow \mathrm{Fe}\left(\mathrm{C}_{2} \mathrm{O}_{4}\right)_{3}^{3-}+3 \mathrm{H}^{+}+2 \mathrm{H}_{2} \mathrm{O} \\
\mathrm{Fe}^{3+}+\mathrm{C}_{2} \mathrm{O}_{4}{ }^{2-} \rightarrow \mathrm{Fe}\left(\mathrm{C}_{2} \mathrm{O}_{4}\right)^{+} \\
\mathrm{Fe}\left(\mathrm{C}_{2} \mathrm{O}_{4}\right)^{+}+\mathrm{C}_{2} \mathrm{O}_{4}{ }^{2-} \rightarrow \mathrm{Fe}\left(\mathrm{C}_{2} \mathrm{O}_{4}\right)_{2}^{-} \\
\mathrm{Fe}\left(\mathrm{C}_{2} \mathrm{O}_{4}\right)_{2}^{-}+\mathrm{C}_{2} \mathrm{O}_{4}^{2-} \rightarrow \mathrm{Fe}\left(\mathrm{C}_{2} \mathrm{O}_{4}\right)_{3}^{3-}
\end{gathered}
$$

\subsubsection{Effect of Solid/Liquid(S/L) Ratio}

The effect of S/L ratio on the extraction efficiency of iron were studied. The results are showed in Figure 3. As can be seen, Fe extraction ratio increased gradually with leaching time and reached equilibrium within $3 \mathrm{~h}$. Meanwhile, when the S/L ratio changed from 1:20 to 1:60, final Fe extraction ratio increased from $90.12 \%$ to $96.13 \%$. The reason is that certain oxalic acid concentration is much more than that of theoretical requirement with the decrease of solid content, resulting in the promotion of Reaction (1) [14]. This indicate that the smaller of S/L ratio, the higher the Fe extraction ratio is. When more lixiviant used at a S/L ratio higher than 1:50 and there was no significant change in Fe extraction ratio [29]. Therefore, the optimal S/L ratio of 1:50 was chosen for further study. 


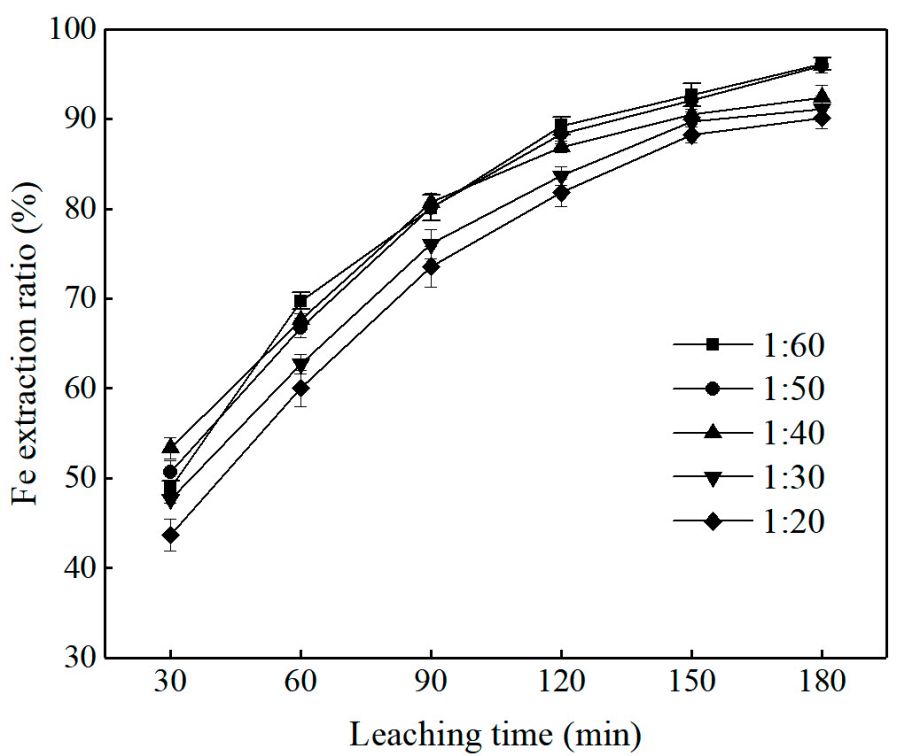

Figure 3. Fe leaching ratio with different $\mathrm{S} / \mathrm{L}$ ratio. (Temperature, $95^{\circ} \mathrm{C}$; oxalic acid concentration, $0.40 \mathrm{~mol} / \mathrm{L}$; stirring rate, $300 \mathrm{r} / \mathrm{min}$ ).

\subsubsection{Effect of Oxalic Acid Concentration}

Figure 4 shows the effect of oxalic acid addition on the Fe extraction ratio. From Figure 4, final Fe extraction ratio gradually increased with the increase of oxalic acid concentration. The increasing Fe extraction ratio of $20.32 \%$ is acquired when oxalic acid addition increased from $0.24 \mathrm{~mol} / \mathrm{L}$ to $0.40 \mathrm{~mol} / \mathrm{L}$. This is due to that higher oxalic acid concentration would benefit to the reaction process of Reaction (1). However, excessive oxalic acid concentration has little extra promotion on the leaching process of iron and the leaching cost would be increased. Hence, the addition of $0.40 \mathrm{~mol} / \mathrm{L}$ was selected as the optimal oxalic acid addition.

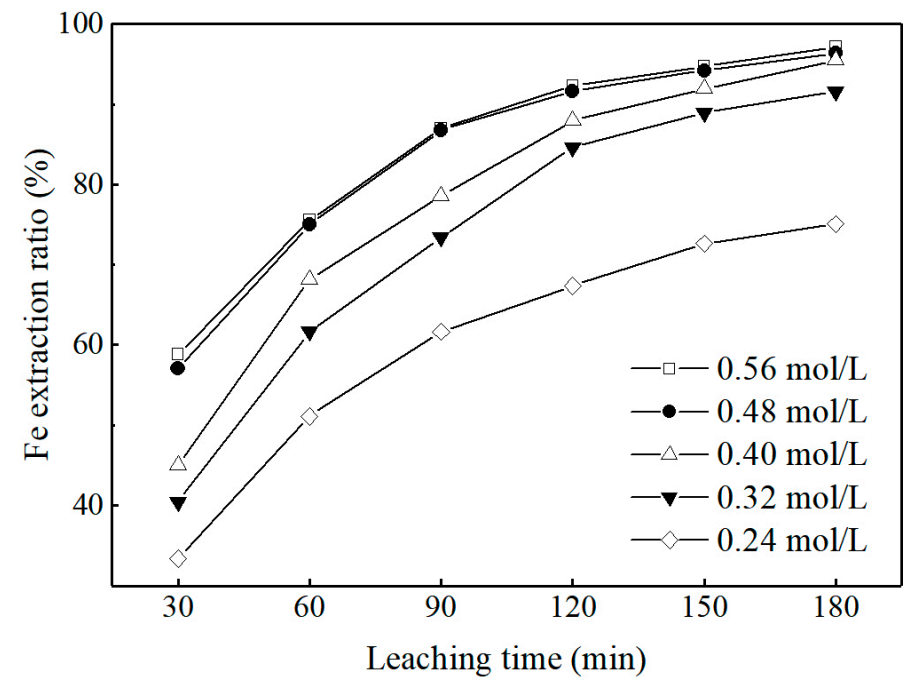

Figure 4. Fe leaching ratio with different oxalic acid addition. (Temperature, $95^{\circ} \mathrm{C}$; S/L ratio, 1:50; stirring rate, $300 \mathrm{r} / \mathrm{min}$ ).

\subsubsection{Effect of Leaching Temperature}

The temperature of leaching solution was varied from $55{ }^{\circ} \mathrm{C}$ to $95{ }^{\circ} \mathrm{C}$ with intervals of $10{ }^{\circ} \mathrm{C}$ to study the effect of leaching temperature on the leaching of iron from slag, and the results are showed 
in Figure 5. It is found that the Fe extraction ratio increase greatly with leaching solution temperature. Accordingly, the first-rank leaching temperature of $95^{\circ} \mathrm{C}$ was chosen.

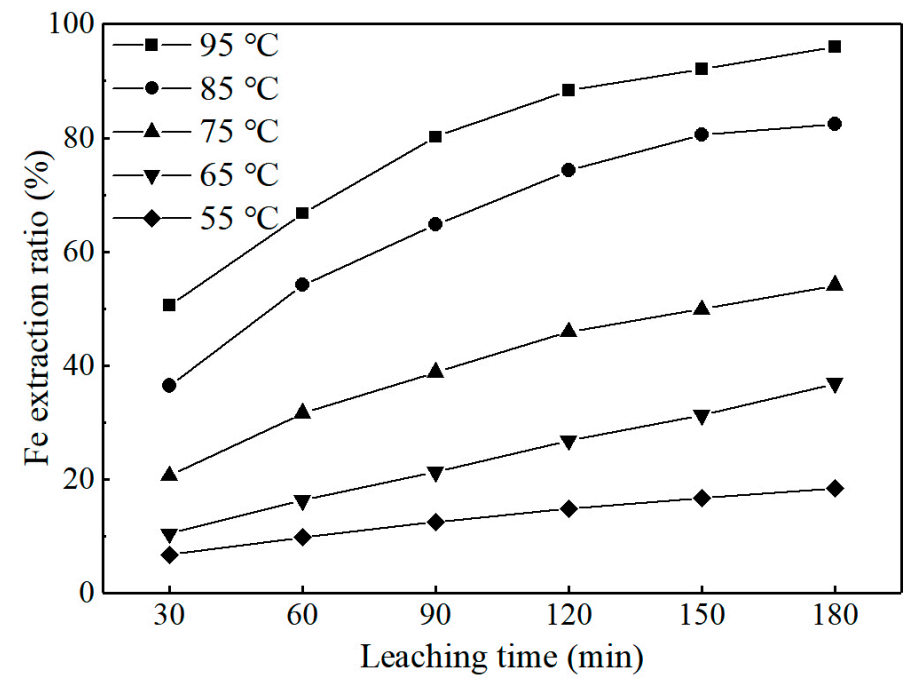

Figure 5. Fe leaching ratio with different leaching temperature. (S/L ratio, 1:50; oxalic acid concentration, $0.40 \mathrm{~mol} / \mathrm{L}$; stirring rate, $300 \mathrm{r} / \mathrm{min}$ ).

\subsubsection{Effect of Stirring Rate}

Figure 6 shows the experimental results of stirring rate impact on the leaching of iron. It indicates that the Fe extraction ratio of the groups of both $100 \mathrm{r} / \mathrm{min}$ and $500 \mathrm{r} / \mathrm{min}$ are lower than that of $300 \mathrm{r} / \mathrm{min}$. Under the condition of low stirring rate, most of slags deposit at the bottom of reaction container due to lack of stirring intensity, causing insufficiently contacting with oxalic acid and decreased the Fe extraction ratio. The inner wall of 3-neck, round bottom flask is smooth without any baffles. When increasing agitation rate, a swirl phenomenon could be appeared in 3-neck, round bottom flask, which the liquid makes circumference movement along the inner wall of the flask. For the solid-liquid suspension system, the swirl phenomenon could promote stratification and separation between solid and liquid, and then the solid will be thrown to the bottom of flask [30]. This will reduce the contact time between slag and oxalic acid, resulting in decrease of Fe extraction ratio. So, the stirring rate of $300 \mathrm{r} / \mathrm{min}$ was selected as the optimal condition.

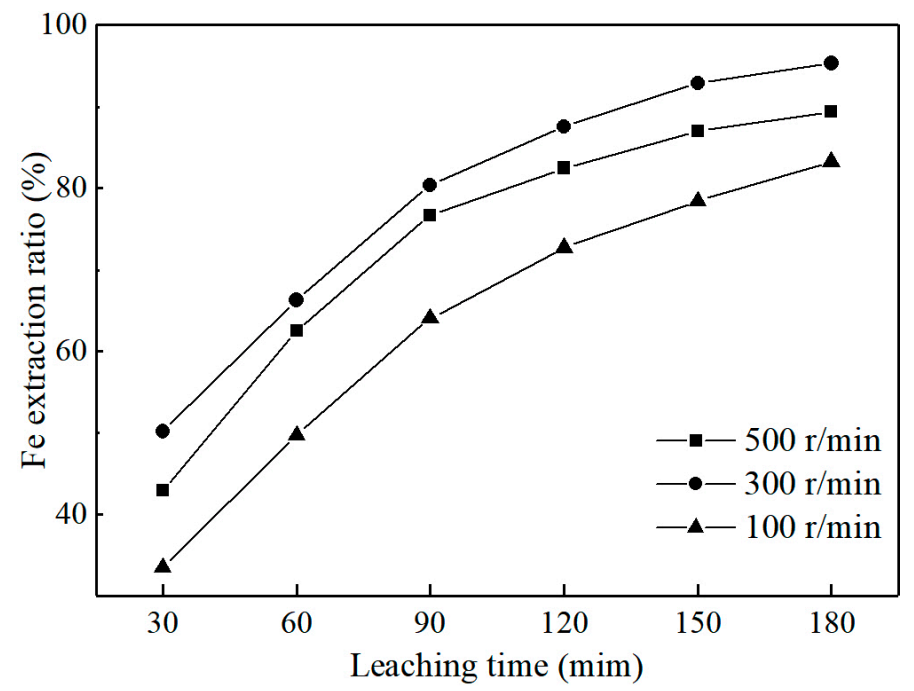

Figure 6. Fe leaching ratio with the increase of leaching time at different stirring rate. (Temperature, $95{ }^{\circ} \mathrm{C}$; S/L ratio, 1:50; oxalic acid concentration, $0.40 \mathrm{~mol} / \mathrm{L}$ ). 


\subsection{Irradiation of $\left[\mathrm{Fe}\left(\mathrm{C}_{2} \mathrm{O}_{4}\right)_{n}\right]^{(3-2 n)+}$ Solution with Ultraviolet Light}

Rapid photochemical reaction will happen when the stable complex of $\left[\mathrm{Fe}\left(\mathrm{C}_{2} \mathrm{O}_{4}\right)_{n}\right]^{(3-2 n)+}$ is irradiated by ultraviolet light and visible light (Reaction (5)), and precipitation of ferrous oxalate crystals could be obtained (Reaction (6)). The reactions are presented below [28]:

$$
\begin{gathered}
2\left[\mathrm{Fe}\left(\mathrm{C}_{2} \mathrm{O}_{4}\right)_{\mathrm{n}}\right]^{(3-2 \mathrm{n})+} \stackrel{h v}{\rightarrow} 2 \mathrm{Fe}^{2+}+(2 \mathrm{n}-1) \mathrm{C}_{2} \mathrm{O}_{4}^{2-}+2 \mathrm{CO}_{2} \\
\mathrm{Fe}^{2+}+\mathrm{C}_{2} \mathrm{O}_{4}^{2-}+2 \mathrm{H}_{2} \mathrm{O} \rightarrow \mathrm{FeC}_{2} \mathrm{O}_{4} \cdot 2 \mathrm{H}_{2} \mathrm{O} \downarrow
\end{gathered}
$$

\subsubsection{Effect of Irradiation Wavelengths}

At a molar ratio of iron to oxalic acid of 1:4, the optimal conditions of wavelength and irradiation time were determined. It is seen from Figure 7 , the final Fe precipitate recovery ratio was highest at $98.1 \%$ when the wavelength of ultraviolet light was $254 \mathrm{~nm}$ or $365 \mathrm{~nm}$. Compared to the wavelength at $365 \mathrm{~nm}$, high iron recovery efficiency could be obtained in a shorter time at $254 \mathrm{~nm}$. The photon energy order of $254 \mathrm{~nm}$ and $365 \mathrm{~nm}$ is $254 \mathrm{~nm}>365 \mathrm{~nm}$, the reaction speed at $254 \mathrm{~nm}$ is faster in a short period of time. This is the reason why the Fe precipitate recovery ratio of $254 \mathrm{~nm}$ and $365 \mathrm{~nm}$ has huge difference at $15 \mathrm{~min}$. As the reaction continues, the Fe precipitate recovery ratio of $254 \mathrm{~nm}$ and $365 \mathrm{~nm}$ is alike Therefore, the wavelength of $254 \mathrm{~nm}$ was chosen for irradiation and the optimum irradiation time is $30 \mathrm{~min}$ in this study.

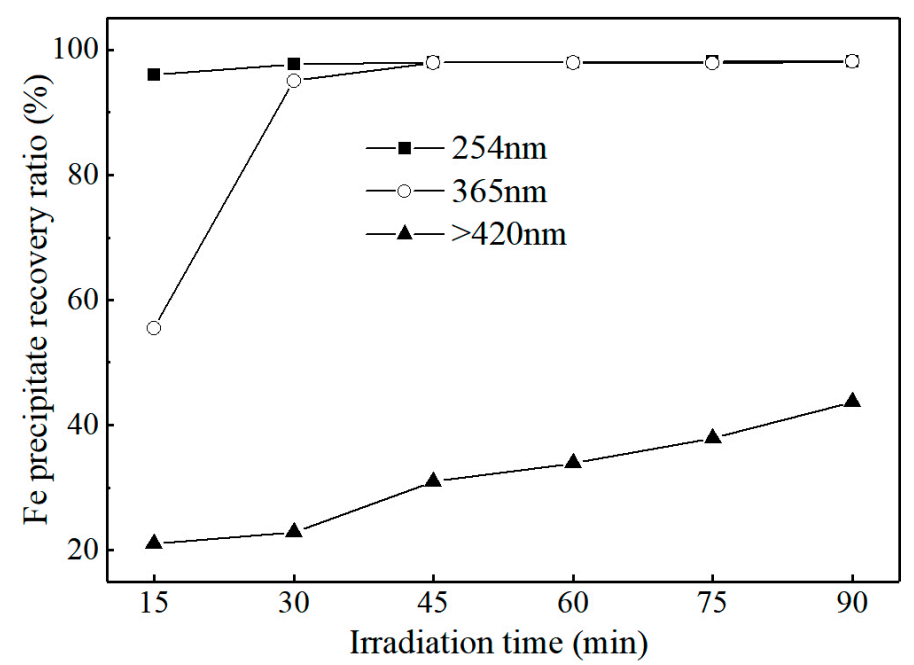

Figure 7. Fe precipitate recovery with the increase of irradiation time at different wavelengths.

\subsubsection{Effect of Iron and Oxalic Acid}

Under the condition that the ultraviolet light wavelength was $254 \mathrm{~nm}$, the effect of ratio of Fe and oxalic acid were studied. At present in Figure 8 that the Fe precipitate recovery ratio increase greatly with the decrease of the ratio of iron and oxalic acid after $30 \mathrm{~min}$ of irradiation, and reached steady state at $97.75 \%$ at the iron to oxalic acid molar ratio of $1: 4$; it is only $0.46 \%$ lower than the molar ratio of 1:6. The complex of $\mathrm{Fe}\left(\mathrm{C}_{2} \mathrm{O}_{4}\right)^{+}, \mathrm{Fe}\left(\mathrm{C}_{2} \mathrm{O}_{4}\right)_{2}$, , and $\mathrm{Fe}\left(\mathrm{C}_{2} \mathrm{O}_{4}\right)_{3}{ }^{3-}$ could be detected in leaching solution, but molar absorbance is highest for $\mathrm{Fe}\left(\mathrm{C}_{2} \mathrm{O}_{4}\right)_{3}{ }^{3-}$ [31], a large amount of $\mathrm{Fe}\left(\mathrm{C}_{2} \mathrm{O}_{4}\right)_{3}{ }^{3-}$ is propitious to precipitating and recovering of iron. At the same time, some researchers presented that the larger of molar ratio, the more unfavorable to the formation of $\mathrm{Fe}\left(\mathrm{C}_{2} \mathrm{O}_{4}\right)_{3}{ }^{3-}$ [24]. However, a smaller molar ratio will result in an increase in oxalic acid waste. So, the molar ratio of 1:4 for iron to oxalic acid was chosen to obtain a higher efficiency of Fe deposition and oxalic acid utilization. 


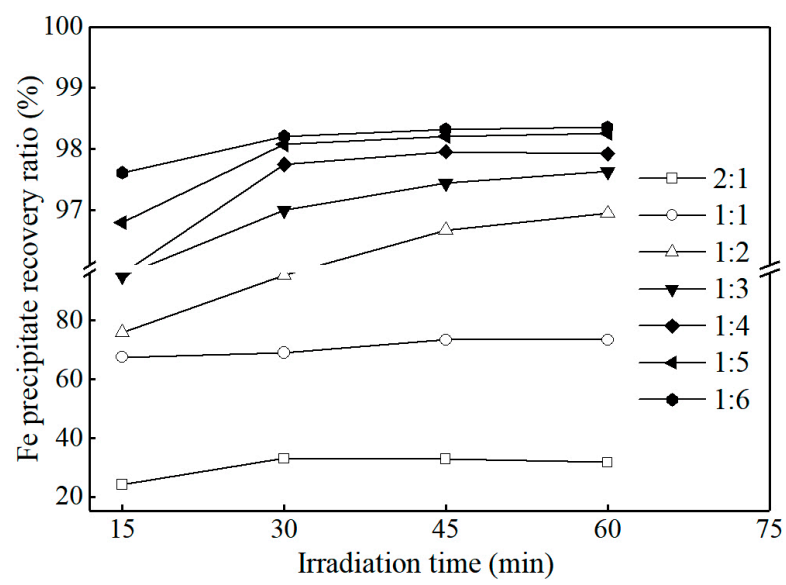

Figure 8. Fe deposition efficiency with the increase of irradiation time at different molar ratios of Fe to oxalic acid.

\subsection{Performance of the Combined Process}

A 9 times' continuous cycle running test was carried out to investigate the stability of the feasibility and stability of the combined process. Table 2 was the experiment conditions for the combined process on the basis of results obtained from Sections 3.2 and 3.3.

Table 2. Experiment conditions.

\begin{tabular}{ccc}
\hline Process & Condition & Value \\
\hline \multirow{4}{*}{ Leaching } & Stirring rate & $300 \mathrm{r} / \mathrm{min}$ \\
& Leaching time & $3 \mathrm{~h}$ \\
& S/L ratio & $1: 50$ \\
& Temperature & $95^{\circ} \mathrm{C}$ \\
& Oxalic acid concentration & $0.40 \mathrm{~mol} / \mathrm{L}$ \\
\hline \multirow{2}{*}{ Irradiation } & Wavelengths & $254 \mathrm{~nm}$ \\
& Irradiation time & $1 \mathrm{~h}$ \\
\hline
\end{tabular}

\subsubsection{Stability of Cycle Running Test}

Figure 9 shows that the extraction and precipitation efficiency of iron in the test of 9 continuous loops, the extraction and precipitation efficiency are fluctuant in a small range. Average of efficiency for the two processes were $96.21 \%$ and $98.71 \%$, respectively. This demonstrate that almost all the iron in slag and leaching solution are leached and precipitated; the stable performance could provide a reference for industrial application.

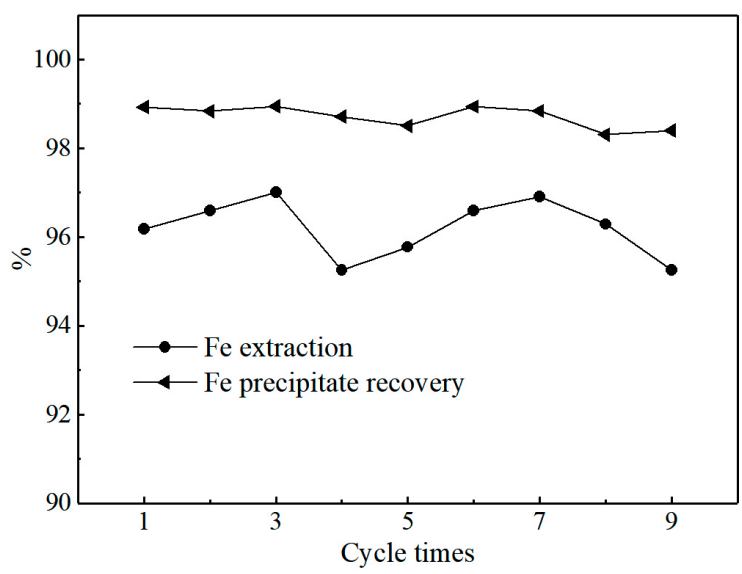

Figure 9. Stabilities of leaching and irradiation process in cycle running. 


\subsubsection{Analysis of Precipitation}

The peaks of XRD pattern of the crystals are consistent with the standard pattern of $\mathrm{FeC}_{2} \mathrm{O}_{4} \cdot 2 \mathrm{H}_{2} \mathrm{O}$ in Figure 10. This indicated that the precipitation crystals were (JCPDS72-1305), and some components content were listed at Table 3, ferrous oxalate content in crystals was up to $99.32 \%$. As can be seen from Figure 11, the strip crystal morphology is obtained by SEM. The ferrous oxalate crystal particles are well-distributed and the morphology is regular, the crystal particles are cuboid rod-shaped-particles, with $8 \sim 18 \mu \mathrm{m}$ length, $3 \sim 8 \mu \mathrm{m}$ wide, and smooth surface. The aspect ratio is $2.3 \sim 5.3$. This is similar to former literature [32].

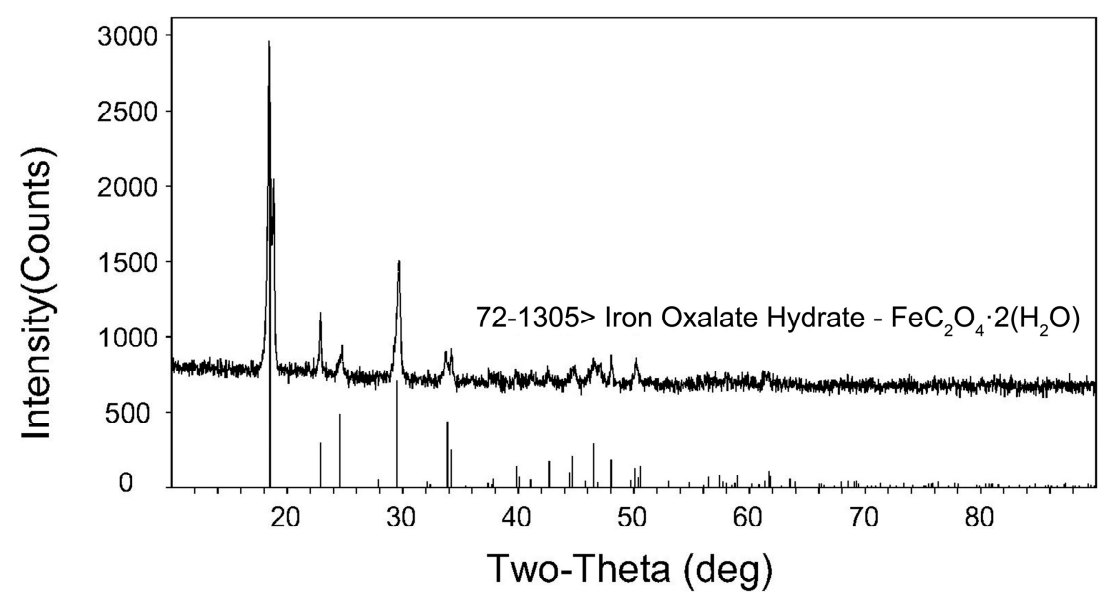

Figure 10. XRD pattern of crystals in irradiation experiment.

Table 3. The content of precipitation crystal ( $w / \%)$.

\begin{tabular}{ccccccc}
\hline $\mathrm{FeC}_{\mathbf{2}} \mathbf{O}_{\mathbf{4}} \cdot \mathbf{2} \mathbf{H}_{\mathbf{2}} \mathbf{O}$ & Water & $\mathbf{C u}$ & $\mathrm{Cr}$ & $\mathbf{N i}$ & $\mathrm{Zn}$ & $\mathrm{Al}$ \\
\hline 99.32 & 0.06 & $5.47 \times 10^{-4}$ & $2.15 \times 10^{-4}$ & $1.29 \times 10^{-4}$ & $7.47 \times 10^{-4}$ & $7.73 \times 10^{-4}$ \\
\hline
\end{tabular}

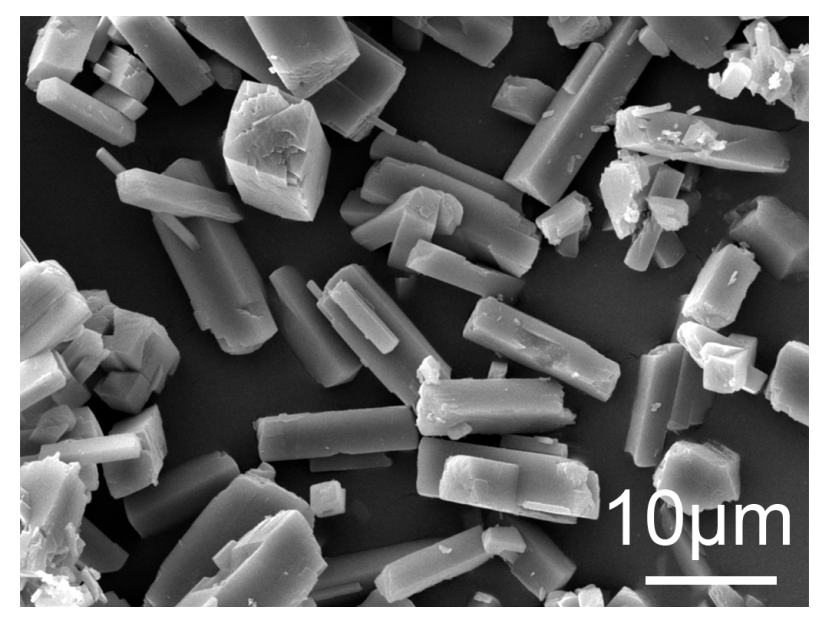

Figure 11. Crystal morphology of irradiation experiment $(\times 2000)$.

\subsubsection{Material Balance}

Material balance of oxalic acid and iron in leaching process and irradiation process were analyzed to discuss feasibility of the combined process. The material flow was showed in Figure 12, and the recovery efficiencies of iron and oxalic acid were listed in Table 4. 


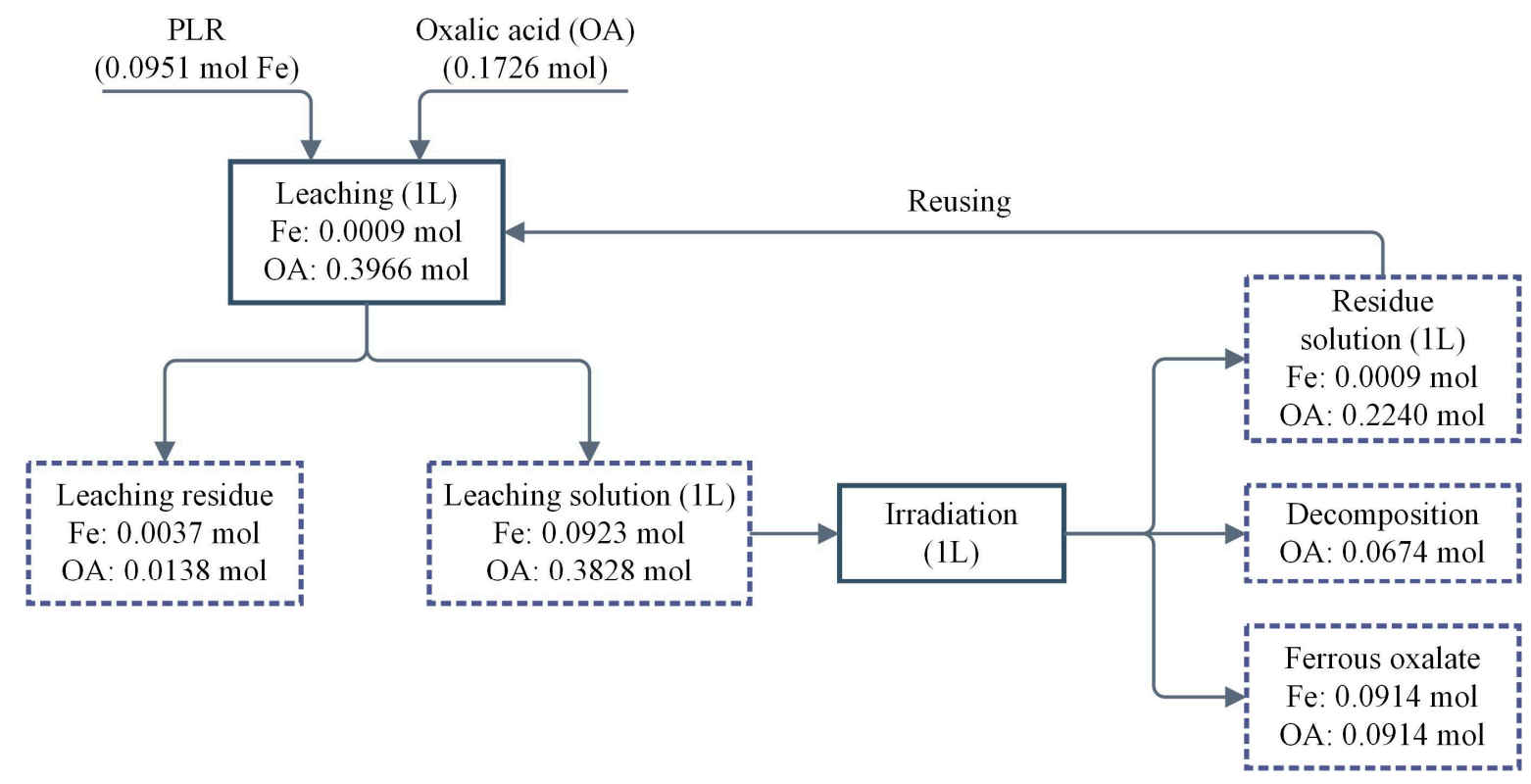

Figure 12. Material balance of oxalic acid and Fe in combined process.

Table 4. Recovery efficiencies of Fe and oxalic acid (\%).

\begin{tabular}{cccc}
\hline Project & Leaching Process & Irradiation Process & Total \\
\hline Fe & 96.11 & 99.02 & 95.17 \\
Oxalic Acid & 96.52 & 58.52 & 56.48 \\
\hline
\end{tabular}

For iron, leaching efficiency, precipitation efficiency, and total recovery efficiency were $96.11 \%$, $99.02 \%$, and $95.17 \%$, respectively. For oxalic acid, in leaching process, the loss ratio is $3.48 \%$; in irradiation process, the recovery efficiency is $58.52 \%$, and the decomposition ratio is $17.61 \%$. The decomposition of oxalic acid consisted of two parts: theoretical and additional. The Reaction (5) indicated that theoretical oxalic acid decomposition was $11.94 \%$, but the actual was over than it. The additional decomposition of oxalic acid may be caused by ultraviolet irradiation and more oxalic acid is needed to provide electrons to convert iron (III) into iron (II).

\section{Conclusions}

(1) In the leaching experiment, the Fe extraction ratio of $95.89 \%$ is reached in the optimal condition of $\mathrm{S} / \mathrm{L}$ ratio at 1:50, oxalic acid concentration at $0.40 \mathrm{~mol} / \mathrm{L}$, leaching temperature at $95{ }^{\circ} \mathrm{C}$, and stirring rate at $300 \mathrm{r} / \mathrm{min}$ within $3 \mathrm{~h}$.

(2) In the irradiation experiment, $97.75 \%$ of iron in leaching solution was precipitated by $30 \mathrm{~min}$ irradiation at $254 \mathrm{~nm}$ ultraviolet light and Fe/oxalic acid molar ratio at 1:4.

(3) In the test of 9 continuous cycles, average leaching and precipitation ratio of iron are $96.21 \%$ and $98.71 \%$, respectively. The ferrous oxalate with grade of $99.32 \%$ was produced from pyrolusite leaching slag by the combined process of oxalic acid leaching and ultraviolet irradiation.

(4) Material balance indicated that $95.17 \%$ of iron is recovered in the form of $\mathrm{FeC}_{2} \mathrm{O}_{4} \cdot 2 \mathrm{H}_{2} \mathrm{O}$ and $58.52 \%$ of oxalic acid is recycled. $17.61 \%$ of oxalic acid was lost in irradiation process, used as reductant to reduce $\mathrm{Fe}^{3+}$ to $\mathrm{Fe}^{2+}$, and decomposed into $\mathrm{CO}_{2}$.

(5) The technology realized the recovery of iron from pyrolusite leaching slag by a lab-scale circulation process of oxalic acid leaching and ultraviolet irradiation, which has extensive applied foreground contributing to its advantages of stable performance, high iron recovery efficiency, and sustainable development. 
Acknowledgments: This project is supported by the National Natural Science Foundation of China (NSFC-51304140 and NSFC-51374150) and Science and Technology Plan Projects of Sichuan Province, China (Grant No. 2015HH0067).

Author Contributions: Biao Deng, Shijun Su, Sanglan Ding and Weiyi Sun conceived and designed the experiments; Biao Deng performed the experiments; Biao Deng and Bozhi Wang analyzed the data; Biao Deng, Bozhi Wang and Weiyi Sun contributed reagents/materials/analysis tools; Biao Deng wrote the paper.

Conflicts of Interest: The authors declare no conflict of interest.

\section{References}

1. Zhang, J.; Zhou, G. A review of manganese ore resources in China and its processing technology process. China's Manganese Ind. 2006, 24, 1-5.

2. Bilinski, H.; Kwokal, Ž.; Branica, M. Formation of some manganese minerals from ferromanganese factory waste disposed in the Krka River Estuary. Water Res. 1996, 30, 495-500. [CrossRef]

3. Senanayake, G. A mixed surface reaction kinetic model for the reductive leaching of manganese dioxide with acidic sulfur dioxide. Hydrometallurgy 2004, 73, 215-224. [CrossRef]

4. Sahoo, R.N.; Naik, P.K.; Das, S.C. Leaching of manganese from low-grade manganese ore using oxalic acid as reductant in sulphuric acid solution. Hydrometallurgy 2001, 62, 157-163. [CrossRef]

5. You, Z.; Li, G.; Zhang, Y.; Peng, Z.; Jiang, T. Extraction of manganese from iron rich $\mathrm{MnO}_{2}$ ores via selective sulfation roasting with $\mathrm{SO}_{2}$ followed by water leaching. Hydrometallurgy 2015, 156, 225-231. [CrossRef]

6. Qiu, C.; Zhou, Z.; Li, M. Research on preparation of unburned bricks using tailings of desulfurization of pyrolusite slurry. J. Chengdu Univ. Sci. Ed. 2014, 33, 398-401.

7. Naik, P.K.; Sukla, L.B.; Das, S.C. Aqueous $\mathrm{SO}_{2}$ leaching studies on Nishikhal manganese ore through factorial experiment. Hydrometallurgy 2000, 54, 217-228. [CrossRef]

8. Naik, P.K.; Nathsarma, K.C.; Das, S.C.; Misra, V.N. Leaching of low grade Joda manganese ore with sulphur dioxide in aqueous medium. Miner. Process. Extr. Metall. 2013, 112, 131-134. [CrossRef]

9. Wang, M.; Zhou, S.; Wang, X.; Chen, B.; Yang, H.; Wang, S.; Luo, P. Recovery of iron from chromium vanadium-bearing titanomagnetite concentrate by direct reduction. JOM 2016, 68, 2698-2703. [CrossRef]

10. Li, M.; Peng, B.; Chai, L.; Peng, N.; Yan, H.; Hou, D. Recovery of iron from zinc leaching residue by selective reduction roasting with carbon. J. Hazard. Mater. 2012, 237, 323-330. [CrossRef] [PubMed]

11. Jiao, R.; Xing, P.; Wang, C.; Ma, B.; Chen, Y.-Q. Recovery of iron from copper tailings via low-temperature direct reduction and magnetic separation: Process optimization and mineralogical study. Int. J. Miner. Metall. Mater. 2017, 24, 974-982. [CrossRef]

12. Tuncuk, A.; Akcil, A. Iron removal in production of purified quartz by hydrometallurgical process. Int. J. Miner. Process. 2016, 153, 44-50. [CrossRef]

13. Ma, B.; Wang, C.; Yang, W.; Yang, B.; Zhang, Y. Selective pressure leaching of Fe (II)-rich limonitic laterite ores from Indonesia using nitric acid. Miner. Eng. 2013, 45, 151-158. [CrossRef]

14. Yang, Y.; Wang, X.; Wang, M.; Wang, H.; Xian, P. Recovery of iron from red mud by selective leach with oxalic acid. Hydrometallurgy 2015, 157, 239-245. [CrossRef]

15. Taxiarchou, M.; Panias, D.; Douni, I.; Paspaliaris, I.; Kontopoulos, A. Removal of iron from silica sand by leaching with oxalic acid. Hydrometallurgy 1997, 46, 215-227. [CrossRef]

16. Veglió, F.; Passariello, B.; Barbaro, M.; Plescia, P.; Marabini, A.M. Drum leaching tests in iron removal from quartz using oxalic and sulphuric acids. Int. J. Miner. Process. 1998, 54, 183-200. [CrossRef]

17. Sobianowska-Turek, A.; Szczepaniak, W.; Maciejewski, P.; Gawlik-Kobylińska, M. Recovery of zinc and manganese, and other metals ( $\mathrm{Fe}, \mathrm{Cu}, \mathrm{Ni}, \mathrm{Co}, \mathrm{Cd}, \mathrm{Cr}, \mathrm{Na}, \mathrm{K}$ ) from $\mathrm{Zn}-\mathrm{MnO}_{2}$ and $\mathrm{Zn}-\mathrm{C}$ waste batteries: Hydroxyl and carbonate co-precipitation from solution after reducing acidic leaching with use of oxalic acid. J. Power Sources 2016, 325, 220-228. [CrossRef]

18. Ma, Y.; Du, X.; Shen, Y.; Li, G.; Li, M. Crystallization and beneficiation of magnetite for iron recycling from nickel slags by oxidation-magnetic separation. Metals 2017, 7, 321. [CrossRef]

19. Zhou, Y.; Yang, H.; Xue, X.; Yuan, S. Separation and recovery of iron and rare earth from bayan obo tailings by magnetizing roasting and ( $\mathrm{NH} 4)_{2} \mathrm{SO}_{4}$ activation roasting. Metals 2017, 7, 195. [CrossRef]

20. Ambikadevi, V.R.; Lalithambika, M. Effect of organic acids on ferric iron removal from iron-stained kaolinite. Appl. Clay Sci. 2000, 16, 133-145. [CrossRef] 
21. Lahiri, A. Influence of ascorbate and oxalic acid for the removal of iron and alkali from alkali roasted ilmenite to produce synthetic rutile. Ind. Eng. Chem. Res. 2010, 49, 8847-8851. [CrossRef]

22. Peng, A.; He, Z.; Yu, C.; Xiao, W.; Zhuang, X.; Liu, Y. Research on preparation of battery-grade ferrous oxalate from by-product ferrous sulfate. Inorg. Chem. Ind. 2012, 44, 60-62.

23. Heelan, J.; Gratz, E.; Zheng, Z.; Wang, Q.; Chen, M.; Apelian, D.; Wang, Y. Current and prospective Li-Ion battery recycling and recovery processes. JOM 2016, 68, 2632-2638. [CrossRef]

24. Zhang, T.; Wu, S.; Zhu, Z. Photochemical properties and application of ferric-oxalate complexes. Jiangxi Chem. Ind. 2008, 26-29.

25. Yu, Z.; Shi, Z.; Chen, Y.; Niu, Y.; Wang, Y.; Wan, P. Red-mud treatment using oxalic acid by UV irradiation assistance. Trans. Nonferrous Met. Soc. China 2012, 22, 456-460. [CrossRef]

26. Sun, W.; Su, S.; Wang, Q.; Ding, S. Lab-scale circulation process of electrolytic manganese production with low-grade pyrolusite leaching by $\mathrm{SO}_{2}$. Hydrometallurgy 2013, 133, 118-125. [CrossRef]

27. Panias, D.; Taxiarchou, M.; Paspaliaris, I.; Kontopoulos, A. Mechanisms of dissolution of iron oxides in aqueous oxalic acid solutions. Hydrometallurgy 1996, 42, 257-265. [CrossRef]

28. Zuo, Y.; Hoigne, J. Formation of hydrogen-peroxide and depletion of oxalic-acid in atmospheric water by photolysis of iron(III) oxalato complexes. Environ. Sci. Technol. 1992, 26, 1014-1022. [CrossRef]

29. Mazurek, K. Recovery of vanadium, potassium and iron from a spent vanadium catalyst by oxalic acid solution leaching, precipitation and ion exchange processes. Hydrometallurgy 2013, 134-135, 26-31. [CrossRef]

30. Jia, S.; Cai, C. Process Design for Unit Operations of Chemical Engineering; Tianjin University: Tianjin, China, 2011; ISBN 978-7-5618-4112-9.

31. Vincze, L.; Papp, S. Individual quantum yields of $\mathrm{Fe}^{3+} \mathrm{OX}_{\mathrm{n}}{ }^{2-} \mathrm{H}_{\mathrm{m}}{ }^{+}$complexes in aqueous acidic solutions $\left(\mathrm{OX}^{2-} \equiv \mathrm{C}_{2} \mathrm{O}_{4}{ }^{2-}, n=1-3, m=0,1\right)$. J. Photochem. 1987, 36, 289-296. [CrossRef]

32. Zhang, K.; Yang, X.; Wu, J.; Huang, X.; Yao, Y. Optimization of the process parameters for the synthesis process of battery-grade ferrous oxalate by response surface method. Nano 2016, 11, 1650123. [CrossRef]

(C) 2017 by the authors. Licensee MDPI, Basel, Switzerland. This article is an open access article distributed under the terms and conditions of the Creative Commons Attribution (CC BY) license (http:// creativecommons.org/licenses/by/4.0/). 